\title{
1 Monitoring transient groundwater fluxes using the Finite Volume Point Dilution Method
}

2

$4{ }^{1}$ University of Liège, Fac. Applied Sciences, Urban \& Environmental Engineering Research Unit (UEE), Geo ${ }^{3}$ -

5 Hydrogeology and Environmental Geology, Building B52, 4000 Sart Tilman, Belgium. Serge.Brouyere@ulg.ac.be

\section{Keywords}

7 Finite Volume Point Dilution Method, Transient groundwater flux, Single-well tracer test.

\section{Research Highlights}

9 A generalization of the FVPDM is proposed for monitoring transient groundwater fluxes

A flow chart is proposed to dimension transient FVPDM experiments 


\section{Abstract}

Classic estimates of groundwater fluxes are usually based on the application of Darcy's law, which can lead to large imprecisions in transient groundwater flow cases. There is a need for direct, in situ measurement techniques able to monitor time-variable groundwater fluxes. The investigation presented here demonstrates that the Finite Volume Point Dilution Method (FVPDM) is a promising technique for the continuous monitoring of groundwater fluxes. The experimental configuration consisted of monitoring transient groundwater fluxes generated by a multiple step pumping test, which was undertaken in the alluvial aquifer of the River Meuse, Liège (Belgium). Additionally, two FVPDM tests were simultaneously performed in two piezometers screened at two different depths in the alluvial aquifer. Tracer concentration changes during the FVPDM tests were interpreted as the consequences of Darcy flux changes in the alluvial aquifer, which was related to changes in the applied pumping rate. Piezometric levels were also monitored in piezometers located around the pumping well. The pumping test was interpreted using classical analytical solutions, and the FVPDM tests were interpreted using a new mathematical solution, which allows for calculating changes in Darcy fluxes based on the FVPDM tracer concentration evolution during transient groundwater flow conditions. The experiment demonstrated the FVPDM's ability to monitor, as well as be sensitive to changes in transient groundwater fluxes. The FVPDM interpretation also showed contrasting results between the upper part of the aquifer, which is made of loam and sand and slow groundwater flows prevail, and the lower part of the aquifer, which is made of gravels and pebbles and intense groundwater flows prevail. 


\section{Introduction}

In many different hydrogeological contexts, groundwater flow is intrinsically transient and assuming steady state conditions may not be adequate. This is the case for groundwater-surface water interactions (Dujardin et al. 2014, Battle-Aguilar et al. 2014) or tidal effects (Ataie-Ashitani et al 2001), where variations in surface water levels often induce rapid and significant changes in hydraulic gradients and groundwater fluxes. This can also occur in sectors of groundwater catchments characterized by preferential pathways, where intense rainfall events lead to fast recharge mechanisms and accelerated groundwater flow (Lubczynskia \& Gurwinb 2005). Changes in groundwater flow can also be caused by human activities related to groundwater abstraction well operations (Jamin et al. 2015) or overly intense irrigation. Such groundwater flow variations may be characterized by very different time scales, from short tidal or daily barometric to longer seasonal and annual variations (Dentz \& Carrera 2005).

Rein et al. (2009) emphasized the influence of temporally variable groundwater flow conditions on point measurements and contaminant mass flux estimates, which demonstrates the numerous challenges posed by these transient groundwater fluxes. Rolle et al. (2009) also shown that transient flow conditions and physical heterogeneity have a determinant influence on transverse dispersion which contributes to a large extent to mixing and mixing-controlled reactions at the plume fringe between pollutants and electron donors or acceptors. All these contexts and examples illustrate how important is a detailed understanding of the dynamics of groundwater fluxes for sound hydrogeological characterization in general, and more specifically for complex investigations and quantification of reactive transport and attenuation of pollutants in groundwater.

Accurate estimates of groundwater fluxes based on Darcy's law strongly depend on the quality of hydraulic conductivity estimates (based on the interpretation of hydraulic tests) and on the accuracy of hydraulic gradients calculated based on piezometric measurements. In addition, such estimates can 
only deliver a mean value of groundwater flux that is spatially averaged over the area where the hydraulic tests are undertaken and where piezometric heads are measured, which corresponds to the measurement period. This emphasizes the need for direct in situ measurements and monitoring of groundwater fluxes (Bright et al. 2002, Devlin 2016).

Kempf et al. (2013) reviewed different techniques for measuring groundwater fluxes in an aquifer influenced by tidal variations. Heat-Pulse flow meter (HPFM) (Bayless et al. 2011), passive flux meter (PFM) (Hatfield et al. 2004), point dilution method (PDM) (Drost et al. 1968) and point velocity probes (PVP) (Devlin et al 2009, 2011) were applied to measure transient groundwater fluxes. The PDM, HPFM and PVP techniques require several minutes to hours to quantify the groundwater flux. This is because these methods are based on the concentration decline interpretation of a solute or heat tracer. These methods must be undertaken sequentially to obtain successive, yet temporally time-averaged estimates of groundwater flux. Passive flux measurement techniques such as PFM also provide robust estimates of mean groundwater fluxes, which are integrated over the period of passive sampler deployment. However, it cannot show any groundwater flux variation over time.

The Finite Volume Point Dilution Method (FVPDM) (Brouyère et al. 2008) is a generalization of the PDM technique, in which the tracer is continuously injected into the tested well at a controlled, lowflow injection rate. The method was tested successfully in porous and fractured media (Brouyère et al. 2008, Goderniaux et al. 2010, Jamin et al. 2015), which demonstrates its high sensitivity and accuracy. In 2015, Jamin et al. highlighted the sensitivity of the FVPDM technique to transient groundwater flow. However, in that study, the low storage coefficient of the tested, fractured rocks allowed for the simplification of the transient state generated by pumping changes in the aquifer, and this also allowed for a succession of steady state steps, on which the analytical solution of Brouyère et al. 2008 could be applied to interpret the FVPDM experiments. In other groundwater environments, the transient state may induce variations in groundwater fluxes over a shorter time span than the duration required for the FVPDM to stabilize. In these cases, the steady state FVPDM is no longer applicable. 
Starting from these observations and conclusions, the aim of the investigations presented here is to develop the interpretation framework needed for monitoring groundwater fluxes over time using the FVPDM applied tracer technology. For the first step, the methodology is developed as a generalization of the FVPDM to transient groundwater flow fields. A mathematical formalism is proposed to calculate transient groundwater fluxes as a function of monitored concentrations in a tested well. This formalism is based on a finite difference expression of the FVPDM mass balance differential equation, which was established by Brouyère (2003). For the second step, the developed methodology is tested based on a field experiment under controlled conditions. The experiment consists of monitoring transient groundwater fluxes using FVPDM experiments performed in piezometers located near a pumping well, in which multiple step pumping tests are performed to generate transient groundwater flow conditions in an alluvial aquifer. After providing a description of the methodology and experimental configuration, the groundwater flux monitoring results are discussed. 


\section{FVPDM experimental configuration and interpretation schema for transient groundwater flow systems}

In its basic configuration, the FVPDM is performed by the continuous tracer injection into a well and monitoring the tracer concentration evolution within the tested well (Brouyère et al. 2008). Technically, the FVPDM setup requires two pumps (Figure 1). The first pump is used to inject the tracer fluid at a precise, low-flow rate $\left(Q_{i n j}\right)$. The second pump is used to mix the water column and ensure a homogeneous tracer distribution within the well. Monitoring tracer concentration within the well $\left(C_{w}\right)$ can be achieved using an inline measurement unit placed directly into the well, which is on the circulation loop. Groundwater samples can also be collected during the experiment for tracer concentration measurements in the lab. When groundwater flow $\left(Q_{t}\right)$ crossing the well screen is high, the tracer injected into the well is more diluted, and the tracer concentration measured in the well $\left(C_{w}\right)$ is significantly lower than the injected tracer concentration $\left(C_{i n j}\right)$. In contrast, when the groundwater flow crossing the well screen is low, the tracer injected into the well is less diluted, and its concentration $C_{w}$ is higher.

At the beginning of the FVPDM experiment, the tracer concentration in the well $\left(C_{w}\right)$ increases progressively, until equilibrium is reached between the different groundwater and tracer fluxes (Figure 2). Quantification of the groundwater flux is based on modelling the evolution of concentration of the tracer in the well $\left(C_{w}\right)$, using the analytical solution proposed by Brouyère et al. (2008). If the groundwater flow in the aquifer is nearly steady state, the measured tracer concentration in the well stabilizes (Figure 2 , black line) at a value of $C_{w, s t a b}$, which depends only on the injected tracer concentration $\left(C_{i n j}\right)$, and the ratio between the injection flow rate $\left(Q_{i n j}\right)$ and the groundwater transit flow rate across the screen $\left(Q_{t}\right)$. As pointed out by Jamin et al. (2015), when the steady state plateau is reached, quantification of the transit flow rate is independent of the mixing volume $V_{w}$. This offers an advantage to the FVPDM technique against the classical PDM where, at any time, the tracer 
concentration in the well $C_{w}$ depends on the ratio $Q_{t} / V_{w}$ between the transit flow rate and the mixing

122 volume.

123 If groundwater flow in the aquifer is transient, the tracer concentration in the tested well $\left(C_{w}\right)$ is also

124 transient (Figure 2, blue line). When the groundwater flow increases in the aquifer, the tracer dilution

125 in the well increases, and the measured concentration decreases. Conversely, when the groundwater

126 flow decreases, the tracer dilution in the well decreases, and the measured concentration increases.

127 As for other single well tracer dilution techniques, the FVPDM allows for the calculation of an apparent

128 Darcy flux $q_{a p p}\left[\mathrm{LT}^{-1}\right]$, which is related to the effective Darcy flux in the aquifer $q_{D}$ by a flow distortion

129 coefficient $\alpha_{w}$ that accounts for the convergence or divergence of the flow field in the vicinity of the

130 borehole (Drost et al. 1968). The apparent Darcy flux $q_{a p p}$ is calculated as follows (Equation 1):

$131 \quad \alpha_{w} \quad q_{D}=q_{a p p}=\frac{Q_{t}}{S_{w}}=\frac{Q_{t}}{2 r_{w} e_{s c r}}$

132 where $Q_{t}\left[\mathrm{LT}^{-3}\right]$ is the transit flow rate as measured using the FVPDM experiment, $S_{w}\left[\mathrm{~L}^{2}\right]$ the flowing

133 section perpendicular to the groundwater flow at the level of the well screen, $e_{s c r}[\mathrm{~L}]$ the well screen

134 length and $r_{w}[L]$ the inner radius of the tested well.

135 Based on the geometric configuration of the tested piezometers, it can be shown that the distortion

136 coefficient $\alpha=2.87$ (Supplementary Material 1). In the remaining of the paper, the term Darcy flux will

137 refer implicitly to the apparent Darcy flux.

\section{$138 \quad 2.1$ Generalization of the FVPDM equations to transient state groundwater flow}

139 The mass balance equations applied to water and tracer in the injection well (Equation 2a and 2b) are

140 described in detail in Brouyère (2003).

141

$$
\frac{\partial V_{w}}{\partial t}=\pi r_{w}{ }^{2} \frac{\partial h_{w}}{\partial t}=Q_{i n j}+Q_{t}-Q_{o u t}
$$


143 where $V_{w}\left[\mathrm{~L}^{3}\right]$ is the water volume in the tested well $\left(V_{w}=\pi \times r_{w}{ }^{2} \times h_{w}\right) ; h_{w}[\mathrm{~L}]$ is the height of the water 144 column in the tested well; $Q_{i n j}\left[\mathrm{~L}^{3} \mathrm{~T}^{-1}\right]$ is the tracer fluid injection flow rate; $Q_{t}\left[\mathrm{~L}^{3} \mathrm{~T}^{-1}\right]$ is the flow rate of 145 the groundwater entering the tested well with a tracer concentration of $C_{t}\left[\mathrm{ML}^{-3}\right] ; C_{i n j}\left[\mathrm{ML}^{-3}\right]$ is the 146 tracer concentration in the injected tracer fluid; and $Q_{\text {out }}\left[\mathrm{L}^{3} \mathrm{~T}^{-1}\right]$ is the flow rate leaving the well through 147 the screen, which is carrying the tracer at concentration $C_{w}$. All these variables are time dependent in case of transient groundwater flow, but the tracer injection and concentration $\left(Q_{i n j}\right.$ and $\left.C_{i n j}\right)$ are always known because they are part of the experimental configuration. The water column $h_{w}$ is monitored with time (e.g. using a pressiometric probe) in order to calculated changes in the mixing volume $V_{w}$.

$h_{w} \pi r_{w}{ }^{2} \frac{\partial C_{w}}{\partial t}=Q_{i n j} C_{i n j}-Q_{i n j} C_{w}-Q_{t} C_{w}$ Equation (4) can be solved using an implicit finite difference scheme over the time step $\Delta t=t_{n+1}-t_{n}$.

Assuming no tracer is present initially in groundwater, $C_{t}$ is equal to zero and the term $Q_{t} C_{t}$ simplifies.

$C_{w} \pi r_{w}^{2} \frac{\partial h_{w}}{\partial t}$ can be expressed based on Equation (2a) and introduced in Equation (2b), giving Equation (3).

$C_{w} Q_{i n j}+C_{w} Q_{t}-C_{w} Q_{o u t}+h_{w} \pi r_{w}^{2} \frac{\partial C_{w}}{\partial t}=Q_{i n j} C_{i n j}-Q_{o u t} C_{w}$

The two terms $Q_{\text {out }} C_{w}$ simplify and Equation (3) leads to Equation (4):

Other types of finite difference schemes (e.g. explicit or central) could of course be considered. All time-variable terms $Q_{t}, h_{w}$ and $C_{w}$ are thus expressed at time $t_{n+1}$, i.e. $Q_{t}\left(t_{n+1}\right), h_{w}\left(t_{n+1}\right)$ and $C_{w}\left(t_{n+1}\right)$ respectively; $\frac{\partial C_{w}}{\partial t}$ is approximated over the time step as $\frac{C_{w}\left(t_{n+1}\right)-C_{w}\left(t_{n}\right)}{\Delta t}$. 

established by Brouyère et al. (2008).

$C_{w}\left(t_{n+1}\right)=\left(Q_{i n j} C_{i n j}+\frac{\pi r^{2} h_{w}\left(t_{n+1}\right)}{\Delta t} C_{w}\left(t_{n}\right)\right) /\left(\frac{\pi r^{2} h_{w}\left(t_{n+1}\right)}{\Delta t}+Q_{i n j}+Q_{t}\left(t_{n+1}\right)\right)$

$Q_{t}\left(t_{n+1}\right)=\left(Q_{i n j}\left(C_{i n j}-C_{w}\left(t_{n+1}\right)\right)-h_{w}\left(t_{n+1}\right) \pi r_{w}{ }^{2} \frac{C_{w}\left(t_{n+1}\right)-C_{w}\left(t_{n}\right)}{\Delta t}\right) / C_{w}\left(t_{n+1}\right)$

$C_{w}=C_{i n j} \frac{Q_{i n j}}{Q_{i n j}+Q_{t}}$

Under steady state groundwater flow conditions, $h_{w}$ and $C_{w}$ are constant. In this case, the concentration $C_{w}$ in the tested well should stabilizes and Equation (4) can be expressed as follows:

Equation (8) is equivalent to Equation (16) in Brouyère et al (2008). This will be illustrated further using the results of the transient FVPDM experiment described in Section 3.

\subsection{Dimensioning flow chart of an FVPDM experiment for monitoring transient groundwater fluxes}

In Brouyère et al. (2008), a general flowchart was proposed for dimensioning of a FVPDM experiment undertaken in a steady state groundwater flow field. This flowchart has to be adapted to the case of transient groundwater flow conditions. The critical point in dimensioning the FVPDM is to maintain the injection flow rate $\left(Q_{i n j}\right)$ below the critical flow rate $\left(Q_{c r}=\pi \times Q_{t}\right)$, as well as to keep the tracer concentration in the tested well $\left(C_{w}\right)$ within the detection range of the detector. When groundwater 
fluxes decrease in the aquifer, the transit groundwater flow $\left(Q_{t}\right)$ across the screen decreases, and the critical injection rate $\left(Q_{c r}\right)$ also decreases. Thus, the injection rate $\left(Q_{i n j}\right)$ should be dimensioned according to a minimal estimate of transit groundwater flow across the screens $\left(Q_{t, p r i o r}{ }^{\min }\right)$. In contrast, when groundwater fluxes in the aquifer increase, the transit flow rate $\left(Q_{t}\right)$ across the screen also increases, and a stronger tracer dilution occurs in the tested well. In the extreme case of very strong groundwater flows, the tracer concentration may decrease below the detection limit $\left(C_{D L}\right)$.

Considering all these aspects, the design of an FVPDM field experiment for transient groundwater flux monitoring can be established in six steps (Figure 3):

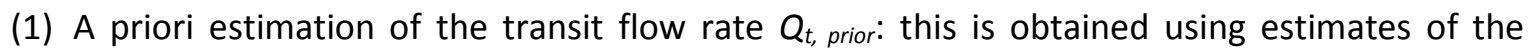
hydraulic conductivity $(K)$ of the tested porous medium and of the hydraulic gradient $(d h / L)$ multiplied by the flow section $\left(S_{w}\right)$ perpendicular to groundwater flow (see Equation 1). Minimal $\left(Q_{t, p r i o r}^{\min }\right)$ and maximal $\left(Q_{t, p r i o r}^{\max }\right)$ expected transit flow rates can be calculated considering maximal and minimal estimates of hydraulic gradient $(d h / L)_{\min }$ and $(d h / L)_{\max }$.

(2) Estimation of the critical injection flow rate $\left(Q_{c r}\right)$ based on the minimal expected transit flow rate $Q_{c r}=\pi \times Q_{t, p r i o r}{ }^{\min }$ (see Brouyère et al. 2008 for details on the relationship).

(3) Definition of the injection flow rate $Q_{i n j}$ as a fraction of $Q_{c r}$ (e.g., $Q_{i n j}=0.1 Q_{c r}$ ) so as to be on the safe side with respect to the a priori estimate of $Q_{c r}$.

(4) Definition of the duration $\left(T_{i n j}\right)$ of the experiment: this depends upon the characteristic time of the transient phenomenon driving changes in groundwater fluxes. For example, it is recommended to measure the tidal effect over 24 or 48 hours to capture 2 or 4 tidal cycles. The tracer injection duration should be at least as long as the characteristic time.

(5) Definition of the volume of tracer fluid $\left(V_{i n j}\right)$ calculated based on $Q_{i n j}$ and $T_{i n j}\left(V_{i n j}=Q_{i n j} \times T_{i n j}\right)$.

(6) Definition of the mass of tracer $\left(M_{i n j}\right)$ to be diluted in $V_{i n j}$ to obtain a tracer concentration $\left(C_{i n j}\right)$ so that $C_{w}$ remains between the detection limit $\left(C_{D L}\right)$ and saturation limit $\left(C_{S L}\right)$ of the detector 

minimal and maximal dilutions expected in the tested well.

207 The use of this flowchart is illustrated using the dimensioning data of the FVPDM experiment 208 performed at Pz19 deep in Section 3. 


\section{Description of the transient FVPDM experiment performed in the} field

\subsection{Experimental test site}

A detailed description of the experimental site can be found in Wildemeersch et al. (2014). The site is in the village of Hermalle-sous-Argenteau, which is $13 \mathrm{~km}$ northeast of the city of Liège in Belgium. The topography of the site is a vast meadow, which lies upon the Meuse River alluvial plain and is nearly flat. The alluvial deposits can be described as follows (Figure 4). The upper soil layer consists of 1 to $1.5 \mathrm{~m}$ of loam with clay lenses. The second layer consists of sandy loam with millimetric gravels, which proportionally increase to a depth of $3 \mathrm{~m}$. From 3 to $10 \mathrm{~m}$ below ground surface, the third layer mainly consists of alluvial sand and gravels. The gravel to sand ratio increases progressively with depth and reaches a zone of clean pebbles, which are frequently more than $20 \mathrm{~cm}$ in diameter and located at the bottom of the alluvial aquifer. This causes a vertical heterogeneity of the alluvial sediments and related hydraulic properties of the presumably assumed homogenous alluvial aquifer. Below the alluvial deposits, low permeability carboniferous shale and sandstone formations constitute the basement of the alluvial aquifer.

The test site is located between the Albert Canal and Meuse River, which controls the piezometric levels in the alluvial aquifer. The groundwater table is located approximately $3.2 \mathrm{~m}$ below ground surface and the piezometric gradient in the alluvial aquifer is on the order of $0.6 \%$ and directed northeast toward the Meuse River. The site is equipped with one large diameter pumping well, 9 single screened piezometers and 9 double-screened piezometers (including Pz19, which was used afterwards for the FVPDM experiments). Pumping tests and tracer tests performed at the site (Brouyère, 2001) allowed for estimating the mean hydraulic conductivity values ranging from $2 \times 10^{-2} \mathrm{~m} / \mathrm{s}$ to $7 \times 10^{-2} \mathrm{~m} / \mathrm{s}$, longitudinal dispersivity values ranging from 0.4 to $5 \mathrm{~m}$ and effective transport porosity values from 3.7 to $8.5 \%$ in the alluvial aquifer. Using Darcy's law with these values of hydraulic gradient and K values, ambient Darcy fluxes in this alluvial aquifer can be estimated in a range between $40 \mathrm{~m} / \mathrm{d}$ and 
and $800 \mathrm{~m} / \mathrm{d}$. Such high values can be explained by the very high hydraulic conductivity of the lower part of the alluvial aquifer constituted by clean large pebbles and by the high hydraulic gradient imposed by the Canal and the River. Groundwater modelling of this alluvial aquifer was carried out by Brouyère (2001) and by Klepikova et al. (2017) and support these values.

\subsection{Experimental methodology and technical setup}

Variable groundwater flow conditions were produced in the alluvial aquifer by pumping at different rates in the pumping well (Figure 5). Two FVPDM experiments were performed simultaneously in piezometer Pz19_shallow and Pz19_deep. Piezometer Pz19 is to be equipped with two internal tubes inserted in the same borehole: one with a $1 \mathrm{~m}$ screen in the upper part of the aquifer where sediments are finer, and one with a $2 \mathrm{~m}$ screen in the lower, coarser part of the aquifer. Pz19 is located 5 meters upgradient from the pumping well (6 inches internal diameter), which is where a submersible pump ( $50 \mathrm{~m}^{3} / \mathrm{h}$ of maximum flow rate) and AquaTROLL level logger are installed. Schlumberger Diver and AquaTROLL level pressiometric loggers were also installed in 6 piezometers ( 2 inches inner diameter): Pz03, Pz06, Pz08, Pz14, Pz19_shallow and Pz19_deep, which are 27, 46, 52, 12 and 5 m distance from the pumping well, respectively.

The two FVPDM tests lasted for 3 days continuously. In both cases, the FVPDM experimental configuration is as follows. A Grundfos MP1 pump is placed at the bottom of the piezometer and connected to the surface with a circulation loop made of $10 / 13 \mathrm{~mm}$ of nylon tubing. At the land surface, the circulation loop is connected to a GGUN FL30 fluorometer, which is placed in line to monitor the tracer concentration $\left(C_{w}\right)$ evolution in the tested piezometer. A Jesco Magdos electromagnetic dosing pump is also connected to the loop to inject the tracer solution. Uranine (CAS $n^{\circ} 518-47-8$ ) and Sulforhodamine $B\left(C A S n^{\circ} 3520-42-1\right.$ ) are used as the fluorescent tracers. Finally, the circulation loop in the piezometer returns down to the groundwater table to simultaneously ensure constant mixing and homogenous concentration of the water volume $\left(V_{w}\right)$ in the well bore. 

according to the flow chart presented in Figure 3 are summarized at Table 1. Previous classical hydrogeological investigations allowed to measure a minimum hydraulic conductivity of the tested alluvial aquifer $\left(K_{\text {est }}{ }^{\mathrm{min}}\right)$ on the order of $2 \times 10^{-2} \mathrm{~m} / \mathrm{s}$ and a minimum hydraulic gradient $\left(\mathrm{dh} / \mathrm{L}^{\mathrm{min}}\right)$ of $0.5 \%$. According to the well characteristics, the screen flowing section $\left(S_{w}\right)$ is equal to $0.091 \mathrm{~m}^{2}$ is which gives an a priori minimum transit flow rate $\left(Q_{t, \text { prior }}{ }^{\mathrm{min}}\right)$ of $9.2 \times 10^{-6} \mathrm{~m}^{3} / \mathrm{s}(0.55 \mathrm{~L} / \mathrm{min})$. This is used to calculate a critical flow rate $\left(Q_{c r}\right)$ of $2.9 \times 10^{-5} \mathrm{~m}^{3} / \mathrm{s}(1.72 \mathrm{~L} / \mathrm{min})$ and a tracer injection flow rate $\left(Q_{i n j}\right)$ of $2.9 \times 10^{-}$ ${ }^{6} \mathrm{~m}^{3} / \mathrm{s}(0.17 \mathrm{~L} / \mathrm{min})$. The expected time of the experiment $\left(T_{i n j}\right)$ is here of 48 hours which leads to a total injection volume of tracer fluid $\left(V_{i n j}\right)$ of approximately $0.5 \mathrm{~m}^{3}$. The tracer solution concentration $\left(C_{i n j}\right)$ is defined to prevent the saturation of the signal of the field fluorometer (corresponding to a tracer concentration of $300 \mathrm{ppb}$ ) while remaining higher than the detection limit (10 ppb). The dilution of the tracer solution depends on the ratio $Q_{i n j} /\left(Q_{t}+Q_{i n j}\right)$ ranging from 0.24 to 0.07 when considering respectively the minimum or maximum transit flow rate. Theoretically, the concentration of the injected tracer $C_{i n j}$ should be set between 144 and $1255 \mathrm{ppb}$ to guarantee that the measured tracer concentration in the well $C_{w}$ remains within the detection limits of the field fluorometer. The final dimensioning of both Pz19_shallow and Pz19_deep is presented in Table 2. The FVPDM monitoring experiment can be divided into 4 phases (Figure 6). The first, which corresponds to the first 12 hours of the experiment, is considered a "warm-up" phase, during which groundwater flow and the two FVPDM injections equilibrate with the pumping conditions generated in the aquifer. The resulting relatively stable tracer concentration reached at the end of this phase is used to calculate an initial groundwater flux value based on the steady state analytical solution from Brouyère et al. (2008). The next three phases (2, 3 and 4) are based on different transient pumping regimes, which are used to evaluate the ability of the transient FVPDM approach, as well as its sensitivity to changes in groundwater fluxes. Phase 2 consisted of 30 minutes of pumping steps with 
284 were reduced to 5 minutes with a step-by-step $1.1 \mathrm{~m}^{3} / \mathrm{h}$ incremental decrease in the pumping rate 285 from 50 to $7.1 \mathrm{~m}^{3} / \mathrm{h}$. This third phase aimed at approaching fully transient groundwater flow conditions 286 in the aquifer to evaluate the FVPDM sensitivity to small and rapid changes in groundwater flow. The 287 fourth and final phase consisted of a multiple step pumping test application with 5 steps of 2 hours 288 each, from 10 to $50 \mathrm{~m}^{3} / \mathrm{h}$ and followed by a recovery period. The objective of this last phase was to compare the results and interpretation of this pumping test to the corresponding changes in piezometric head and groundwater fluxes. 


\section{Results and discussion}

292

293

294

295

296

297

298

299

300

301

302

303

304

305

306

307

The FVPDM experimental results from Pz19_shallow and Pz19_deep, which were completed during the pumping test, are presented in Figure 6 . During the first phase of the experiment, when the pumping rate is maintained at a stable $50 \mathrm{~m}^{3} / \mathrm{h}$ at the pumping well (Figure 6a), the tracer concentrations in the two tested piezometers are constant (Figures 6b and 6d). In Pz19_shallow, the tracer concentration stabilizes 2 hours after beginning the tracer injection at a relative concentration $C_{w} / C_{\text {inj }}$ of 0.12. In Pz19_deep, tracer concentration stabilization occurred more quickly, after less than 15 minutes at a relative concentration of 0.01 . These observations (i.e., shorter time to reach a stabilized concentration and higher tracer dilution at Pz19_deep) reflect the occurrence of larger groundwater fluxes in the deeper part of the alluvial aquifer.

During the phases 2 through 4, the results clearly show that the FVPDM is sensitive to changes in groundwater fluxes. Each change in the pumping rate results in a tracer concentration change in the tested piezometers. When the pumping rate decreases, groundwater fluxes in the aquifer are reduced and tracer concentrations in the tested wells increase due to less dilution. Conversely, each increase in pumping rate induces a decrease in the tracer concentrations in the tested piezometers. When pumping rate variations of $10 \mathrm{~m}^{3} / \mathrm{h}$ are commenced every 30 or 120 minutes, the monitored tracer concentration at Pz19_shallow does not stabilize between pumping steps. At Pz19_deep, stabilization of the tracer concentration is reached faster because of larger groundwater flux occurrences in the deeper part of the alluvial aquifer. During phase 3 , when the pumping rate decreases $1.1 \mathrm{~m}^{3} / \mathrm{h}$ every 5 minutes, the two tested piezometers react progressively without showing any tracer concentration stabilization. Then, groundwater fluxes in the alluvial aquifer can be considered as fully transient. This statement is supported by the monitored piezometric head at the Pz19_deep and Pz19_shallow showing that changes in drawdown takes more than 15 minutes to stabilize to any change of pumping rate (Supplementary Material 2). 
The FVPDM experimental interpretations in terms of groundwater fluxes was performed using

317 Equation (7) (Figures 6c and 6e). Darcy fluxes calculated with Equation (7) can also be compared with manual adjustments of the analytical steady state solution (Equation 8) during specific experimental periods, when the groundwater flows are considered steady state. During step 1 and step 4, the pumping steps were long enough to reach tracer concentration stabilization. Groundwater fluxes calculated by the steady state analytical solution and by the finite difference transient solution are in excellent agreement (Figure 7). This confirms that Equation (7) is an accurate approximation that can be used for the interpretation of FVPDM experiments.

During the first phase of the experiment, when groundwater flows are assumed to be steady state, oscillations in the calculated groundwater fluxes are observed. These oscillations are due to noise in the concentration data measured by the field fluorometer. In piezometer Pz19_shallow, calculated apparent groundwater fluxes vary between $0.35 \mathrm{~m} / \mathrm{d}$ when no pumping is applied and $9.64 \mathrm{~m} / \mathrm{d}$ when pumping at $50 \mathrm{~m}^{3} / \mathrm{h}$. In piezometer Pz19_deep, apparent groundwater fluxes are higher, ranging between $52 \mathrm{~m} / \mathrm{d}$ when no pumping is applied and $321 \mathrm{~m} / \mathrm{d}$ when pumping at $50 \mathrm{~m}^{3} / \mathrm{h}$. During phase 3 , apparent transient groundwater fluxes vary approximately $0.15 \mathrm{~m} / \mathrm{d}$ at Pz19_shallow and $10 \mathrm{~m} / \mathrm{d}$ at Pz19_deep for each decrease of $1.1 \mathrm{~m}^{3} / \mathrm{h}$ in the pumping rate.

The phase 4 multiple step pumping test results are presented in Figure 8, which shows the drawdown measured at the pumping well and monitored piezometers. Each $10 \mathrm{~m}^{3} / \mathrm{h}$ increase in pumping rate leads to an additional stabilized drawdown of $2 \mathrm{~cm}$ at the pumping well and a maximum measured drawdown of $0.11 \mathrm{~m}$ at $50 \mathrm{~m}^{3} / \mathrm{h}$. Noise in the recorded groundwater levels is due to submersible pump turbulence in the well. In piezometers Pz19_shallow and Pz19_deep, the monitored drawdown curves are nearly identical with a maximal cumulative drawdown of $7 \mathrm{~cm}$ observed at $50 \mathrm{~m}^{3} / \mathrm{h}$ and stabilized additive drawdowns of $1.4 \mathrm{~cm}$ for each $10 \mathrm{~m}^{3} / \mathrm{h}$ increase in the pumping rate. Observing similar drawdowns in both piezometer is obvious because they are collocated and screened at two different depths of the same aquifer. The pumping test interpretation using the Dupuit method (1863) and 
measured drawdown at all 6 monitored piezometers gives a mean hydraulic conductivity of $3.26 \times 10^{-}$

${ }^{2} \mathrm{~m} / \mathrm{s}$ (Supplementary Material 3). This similar behavior in the two piezometers, which are screened at different depths in the same aquifer, suggests an identical hydraulic response to pumping in both the upper and lower parts of the aquifer. Nevertheless, the FVPDM measurements indicate that groundwater fluxes are stronger in the lower part than in the upper part of the aquifer, with a difference of almost 2 orders of magnitude (Figure 6). This indicates that the FVPDM technique allows for a more precise characterization of groundwater flux variability compared to the pumping test, which only provides a mean estimate.

In addition, measured groundwater fluxes in Pz19_shallow show a linear increase with an increased pumping rate, and each $10 \mathrm{~m}^{3} / \mathrm{h}$ increment at the pumping well corresponds to an increment of $1.9 \mathrm{~m} /$ day in the measured apparent groundwater flux. At Pz19_deep, measured apparent groundwater fluxes do not vary linearly with an increased pumping rate, but rather, the fluxes follow an exponential increase (Figure 9). The probable explanation is related to the ratio between the groundwater transit flow rate that passes through the well screen and the mixing flow rate used to homogenize the tracer mass on the water column and circulate the water up to the surface to measure the tracer concentration. When pumping at $50 \mathrm{~m}^{3} / \mathrm{h}$ at the pumping well, the groundwater transit flow rate in Pz19_deep is $27 \mathrm{~L} / \mathrm{min}$. The maximum mixing flow rate achieved with the mixing pump is $12 \mathrm{~L} / \mathrm{min}$. Consequently, a significant amount of tracer is carried out of the well before reaching the bottom of the well where the mixing pump circulates it to the surface to be measured by the detector. This results in an underestimated tracer concentration and thus an overestimated groundwater flux. For each increase of the pumping rate at the pumping well, the groundwater flux in the aquifer increases and the overestimation of this groundwater flux increases likewise, amplifying the groundwater flux overestimation and the leading to a nonlinear evolution of the groundwater flux with the pumping rate. To prevent this, the mixing flow rate should always be significantly higher than the groundwater transit flow rate. 


\section{Conclusions}

367

From an operational standpoint, the main result of this research is the generalization of the FVPDM technique for monitoring transient groundwater fluxes. The results have shown that the technique is suitable for this purpose due to a high sensitivity to groundwater flux changes. A finite difference solution has been proposed to fit tracer concentration evolutions monitored in the field during transient FVPDM experiments, as well as to calculate corresponding transient groundwater fluxes. An updated flow chart has also been proposed to dimension transient flux FVPDM experiments.

In previous FVPDM studies, Jamin et al. (2015) measured ranges of groundwater fluxes between 260 and $3300 \mathrm{~m} / \mathrm{d}$ in a fractured aquifer, and Brouyère et al. (2008) measured groundwater fluxes between 0.8 and $3.5 \mathrm{~m} / \mathrm{d}$ in a chalk aquifer and between 0.26 and $27 \mathrm{~m} / \mathrm{d}$ in an alluvial aquifer. Here, the investigated groundwater fluxes ranged between 0.35 and $380 \mathrm{~m} / \mathrm{d}$. Groundwater fluxes across three orders of magnitude were monitored and quantified using an identical experimental configuration, which demonstrates the versatility of the FVPDM in measuring a wide range of groundwater fluxes. Theoretically, there is no minimal or maximal range limit in groundwater fluxes that can be measured using the FVPDM technique, because the experimental configuration can be optimized using either the mixing flow rate, the tracer injection flow rate or the injected tracer concentration. However, measuring groundwater fluxes lower than $0.1 \mathrm{~m} / \mathrm{d}$ using the FVPDM technique may be challenging because of the time required for the tracer concentration to stabilize in the well. This does not constitute a limitation of the FVPDM technique from a physical or technical point of view, but only from an operational point of view due to the required time. In addition, the first part of the evolution of the tracer concentration can still be modelled considering a superposition of two transient effects, i.e. the stabilization of the FVPDM signal and the transient groundwater flow in the aquifer, which might complicate slightly the interpretation. 
Two limitations of using the FVPDM for continuous groundwater flow monitoring can be identified.

391 Selected equipment must withstand the stress of a continuous run for days, while remaining calibrated

392 and accurate. Tracer fluid and energy supplies for the equipment can also be challenging at sites with

393

394

395

396

397

398

399

400

401

402

403

404

405

406

407

408

409

410 limited access. Continuous monitoring of groundwater level variations in the tested well also become mandatory. The second limitation is inherent to the FVPDM technique. The experiment is a priori dimensioned for an expected range of groundwater fluxes. A significant decrease in groundwater flux during the test may lead to an injection flow rate that becomes higher than the critical transit flow rate $\left(Q_{c r}\right)$. In this specific case, the FVPDM test is no longer valid for that low-flow rate period because radially diverging flow conditions develop around the tested well (Brouyère et al. 2008). Monitoring transient groundwater fluxes using the FVPDM technique thus requires regular real time monitoring during the experiment to adapt the injection flow rate $\left(Q_{i n}\right)$ when required.

In the current study, the importance of comparing direct groundwater flux measurements against mean estimates obtained using Darcy's law with mean hydraulic conductivity and hydraulic gradient values has also been demonstrated. The hydraulic conductivity, as estimated based on pumping test results, is a general parameter suitable for evaluating the productivity of the aquifer, but it is not adapted to accurately calculate local groundwater fluxes and associated groundwater flow velocities. The transient FVPDM technique may be applicable to studies in contaminant hydrogeology, where aquifer management is based mainly on the risk of contaminant dispersion. Since groundwater flow is the driving force of contaminant transport and dispersion in the subsurface, having reliable and detailed flux estimates could lead to more accurate pollutant dispersion risk assessment, and ultimately, to optimized management and remediation procedures.

Two perspectives on the development of the FVPDM application can be identified. First, the coupling of this FVPDM flux monitoring with continuous measurement of contaminant concentration will allow for continuous monitoring of contaminant mass flux in groundwater. Second, transient groundwater flow may also be combined with devices sensitive to changes in groundwater flow directions. 


\section{Acknowledgements}

417 This work was supported by the University of Liège [grant no. FSRC-12/81], by the FNRS Belgium [grant

418 no. 1.5060.12] and by the Fondation Roi Baudouin, Prix Ernst Dubois [grant no. 2015-F2812650-

$419204355]$. The authors would like to greatly acknowledge the two reviewers for their pertinent remarks

420 and suggestions that improved the scientific quality of the paper and its overall clarity for the reader. 
422

423

424

425

426

427

428

429

430

431

432

\section{References}

Ataie-Ashtiani, B., Volker, R. E. Lockington, D. A., 2001. Tidal effects on groundwater dynamics in unconfined aquifers. Hydrological Processes, 15(4), 655-669.

http://dx.doi.org/10.1002/hyp.183

Batlle-Aguilar, J., Morasch, B., Hunkeler, D., Brouyère, S., 2014. Benzene dynamics and biodegradation in alluvial aquifers affected by river fluctuations. Groundwater, 52(3): 388-398. http://dx.doi.org/10.1111/gwat.12070

Bayless, E. R., Mandell, W., Ursic, J., 2011. Accuracy of flowmeters measuring horizontal groundwater flow in an unconsolidated aquifer simulator. Ground Water Monitoring and Remediation, 31(2), 48-62. http://dx.doi.org/10.1111/j.1745-6592.2010.01324.x

Bright, J., Wang, F., Close, M., 2002. Influence of the amount of available K data on uncertainty about contaminant transport prediction. Ground Water 40 (5), 529-534. http://dx.doi.org/10.1111/j.1745-6584.2002.tb025

Brouyère, S., 2001. Study and modelling of transport and capturing of solutes in variably saturated media (in French). Ph.D. thesis, 572 pp., Fac. of Appl. Sci., Univ. of Liège, Liège, Belgium. http://hdl.handle.net/2268/40804

Brouyère, S., 2003. Modeling tracer injection and well-aquifer interactions: A new mathematical and numerical approach. Water Resources Research, 39 (3), 1070. http://dx.doi.org/10.1029/2002WR001813, 3. 
Brouyère, S., Batlle-Aguilar, J., Goderniaux, P., Dassargues, A., 2008. A new tracer technique for monitoring groundwater fluxes: The Finite Volume Point Dilution Method, Journal of Contaminant Hydrology, 95 (3-4), 121-140. http://doi.org/10.1016/j.jconhyd.2007.09.001

Dentz, M., Carrera, J., 2005. Effective solute transport in temporally fluctuating flow through heterogeneous media. Water Resources Research, 41, W08414, http://dx.doi.org/10.1029/2004WR003571.

Devlin, J., Tsoflias, G., McGlashan, M., \& Schilling, P., 2009. An inexpensive multi array of sensors for direct groundwater velocity measurement. Groundwater Monitoring \& Remediation, 29(2), 73-77. http://dx.doi.org/10.1111/j.1745-6592.2009.01233.x

Devlin, J., Schillig, P., Bowen, I., Critchley, C., Rudolph, D., Thomson, N., Roberts, J., 2011. Applications and implications of direct groundwater velocity measurement at the centimeter scale. Journal of Contaminant Hydrology, 127, 3-14. http://doi.org/10.1016/j.jconhyd.2011.06.007

Devlin, J.F., 2016. Sensitivity analyses of the theoretical equations used in point velocity probe (PVP) data interpretation. Journal of Contaminant Hydrology, 192, 140-145. http://doi.org/10.1016/j.jconhyd.2016.07.004

Drost, W., Klotz, D., Koch, A., Moser, H., Neumaier, F., Rauert, W., 1968. Point dilution methods of investigating ground water flow by means of radioisotopes. Water Resour. Res., 4 (1), 125146. http://dx.doi.org/10.1029/WR004i001p00125

Dujardin, J., Anibas, C., Bronders, J., Jamin, P., Hamonts, K., Dejonghe, W., Brouyère, S., Batelaan, O., 2014. Combining flux estimation techniques to improve characterization of groundwatersurface-water interaction in the Zenne River, Belgium. Hydrogeology Journal, 22(7), 16571668. https://doi.org/10.1007/s10040-014-1159-4 
Goderniaux, P., Brouyère, S., Gutierrez, A., Baran, N., 2010. Multi-tracer tests to evaluate the hydraulic setting of a complex aquifer system (Brévilles spring catchment, France). Hydrogeology Journal, 18 (7), 1729-1740. http://dx.doi.org/10.1007/s10040-010-0633-x

Hatfield, K., Annable, M., Cho, J., Rao, P.S.C., Klammler, H., 2004. A direct passive method for measuring water and contaminant fluxes in porous media. Journal of Contaminant Hydrology, 75 (3-4), 155-181. http://doi.org/10.1016/j.jconhyd.2004.06.005

Jamin, P., Goderniaux, P., Bour, O., Le Borgne, T., Englert, A., Longuevergne, L., Brouyère, S., 2015. Contribution of the finite volume point dilution method for measurement of groundwater fluxes in a fractured aquifer, Journal of Contaminant Hydrology, 182, 244-255. http://doi.org/10.1016/j.jconhyd.2015.09.002

Kempf, A., Divine, C. E., Leone, G., Holland, S., Mikac, J., 2013. Field Performance of Point Velocity Probes at a Tidally Influenced Site. Remediation, 23: 37-61. http://dx.doi.org/10.1002/rem.21337

Klepikova, M., Wildemeersch, S., Hermans, T., Jamin, P., Orban, P., Nguyen, F., Brouyère, S., Dassargues, A., 2016. Heat tracer test in an alluvial aquifer: Field experiment and inverse modelling, Journal of Hydrology, 540, 812-823. https://doi.org/10.1016/j.jhydrol.2016.06.066.

Lubczynski, M.W., Gurwin, J., 2005. Integration of various data sources for transient groundwater modeling with spatio-temporally variable fluxes-Sardon study case, Spain. Journal of Hydrology, 306 (1-4), 71-96. http://doi.org/10.1016/j.jhydrol.2004.08.038.

Rein, A., Bauer, S., Dietrich, P., \& Beyer, C., 2009. Influence of temporally variable groundwater flow conditions on point measurements and contaminant mass flux estimations. Journal of Contaminant Hydrology, 108(3-4), 118-33. http://doi.org/10.1016/j.jconhyd.2009.06.005 
Rolle, M., Eberhardt, C., Chiogna, G., Cirpka, O. A., Grathwohl, P., Enhancement of dilution and transverse mixing in porous media: Experiments and model-based interpretation. Journal of Contaminant Hydrology, 110, 130-142. http://doi.org/10.1016/j.jconhyd.2009.10.003

Wildemeersch, S., Jamin, P., Orban, P., Hermans, T., Klepikova, M., Nguyen, F., Brouyère, S., Dassargues, A., 2014. Coupling heat and chemical tracer experiments for estimating heat transfer parameters in shallow alluvial aquifers. Journal of Contaminant Hydrology, 169, 90-99. http://doi.org/10.1016/j.jconhyd.2014.08.001 
495 used for the dimensioning of the FVPMD experiment on Pz19_deep.

\begin{tabular}{llll}
\hline Depth of water level & $h_{\text {piezo }}$ & 3 & $\mathrm{~m}$ \\
\hline $\begin{array}{l}\text { Depth of the tested } \\
\text { well }\end{array}$ & $W_{\text {bottom }}$ & 10 & $\mathrm{~m}$ \\
\hline Well radius & $r_{w}$ & 0.025 & $\mathrm{~m}$ \\
\hline Screen length & $e_{s c r}$ & 1.8 & $\mathrm{~m}$ \\
\hline $\begin{array}{l}\text { Volume of water in } \\
\text { the tested well }\end{array}$ & $V_{w}$ & 0.014 & $\mathrm{~m}^{3}$ \\
\hline Surface of flow & $S_{w}$ & 0.091 & $\mathrm{~m}^{2}$ \\
\hline $\begin{array}{l}\text { Temporal dynamic of } \\
\text { the transient flow }\end{array}$ & $T_{C}$ & 48 & $\mathrm{hours}$ \\
\hline $\begin{array}{l}\text { Minimum hydraulic } \\
\text { conductivity }\end{array}$ & $K_{\text {est }}{ }^{\min }$ & $2 \times 10^{-2}$ & $\mathrm{~m} / \mathrm{s}$ \\
\hline $\begin{array}{l}\text { Minimum hydraulic } \\
\text { gradient }\end{array}$ & $d h / L^{\min }$ & 0.5 & $\%$ \\
\hline $\begin{array}{l}\text { Maximum hydraulic } \\
\text { conductivity }\end{array}$ & $K_{e s t}{ }^{\min }$ & $7 \times 10^{-2}$ & $\mathrm{~m} / \mathrm{s}$ \\
\hline $\begin{array}{l}\text { Maximum hydraulic } \\
\text { gradient }\end{array}$ & $d h / L^{\min }$ & 0.6 & $\%$ \\
\hline $\begin{array}{l}\text { Tracer detector } \\
\text { saturation limit }\end{array}$ & $C_{S L}$ & 300 & $\mathrm{ppb}$ \\
\hline $\begin{array}{l}\text { Tracer detector } \\
\text { detection limit }\end{array}$ & $C_{D L}$ & 10 & $\mathrm{ppb}$ \\
\hline
\end{tabular}

496 
499 Table 2: Parameters of the experimental configuration used for FVPDM test at piezometers

500 Pz19_shallow and Pz19_deep.

501

\begin{tabular}{lcccl} 
& $Q_{\text {inj }}\left[\mathrm{m}^{3} / \mathrm{s}\right]$ & $M_{\text {inj }}[g]$ & $C_{\text {inj }}[\mathrm{ppb}]$ & Tracer \\
\hline Pz19_shallow & $5.17 \times 10^{-7}$ & 0.089 & 500 & Sulforhodamine B \\
\hline Pz19_deep & $3.23 \times 10^{-6}$ & 0.558 & 250 & Uranine
\end{tabular}

502 
Tracer injection pump $\mathbf{Q}_{\text {inj }} \quad$ Flowmeter

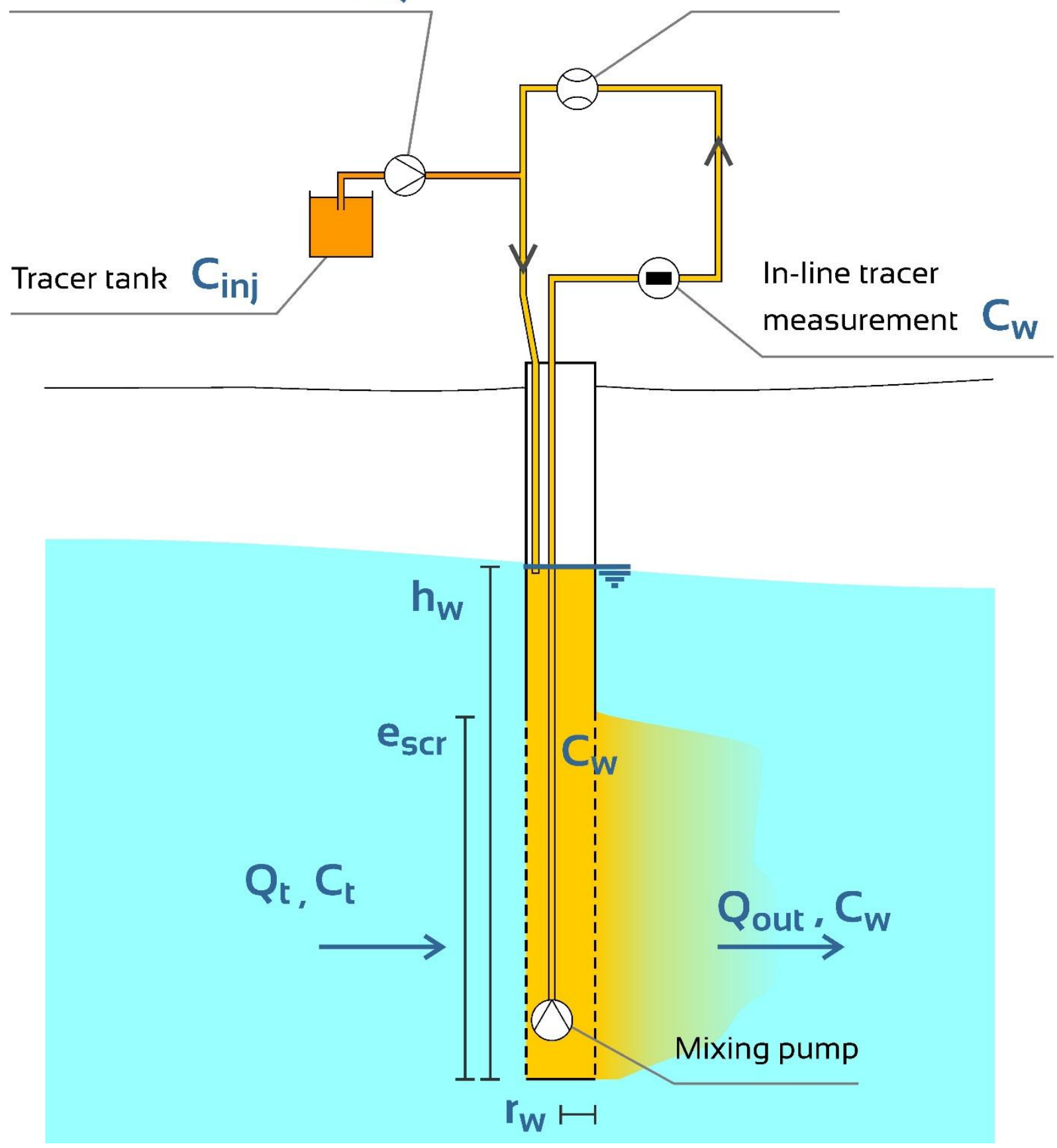

Figure 1: FVPDM experimental configuration. The water volume within the well is constantly mixed

507 using a pump and circulated to the surface, where tracer is injected using a dosing pump.

Concentration of tracer in the loop is monitored using a field fluorometer placed in the line. 


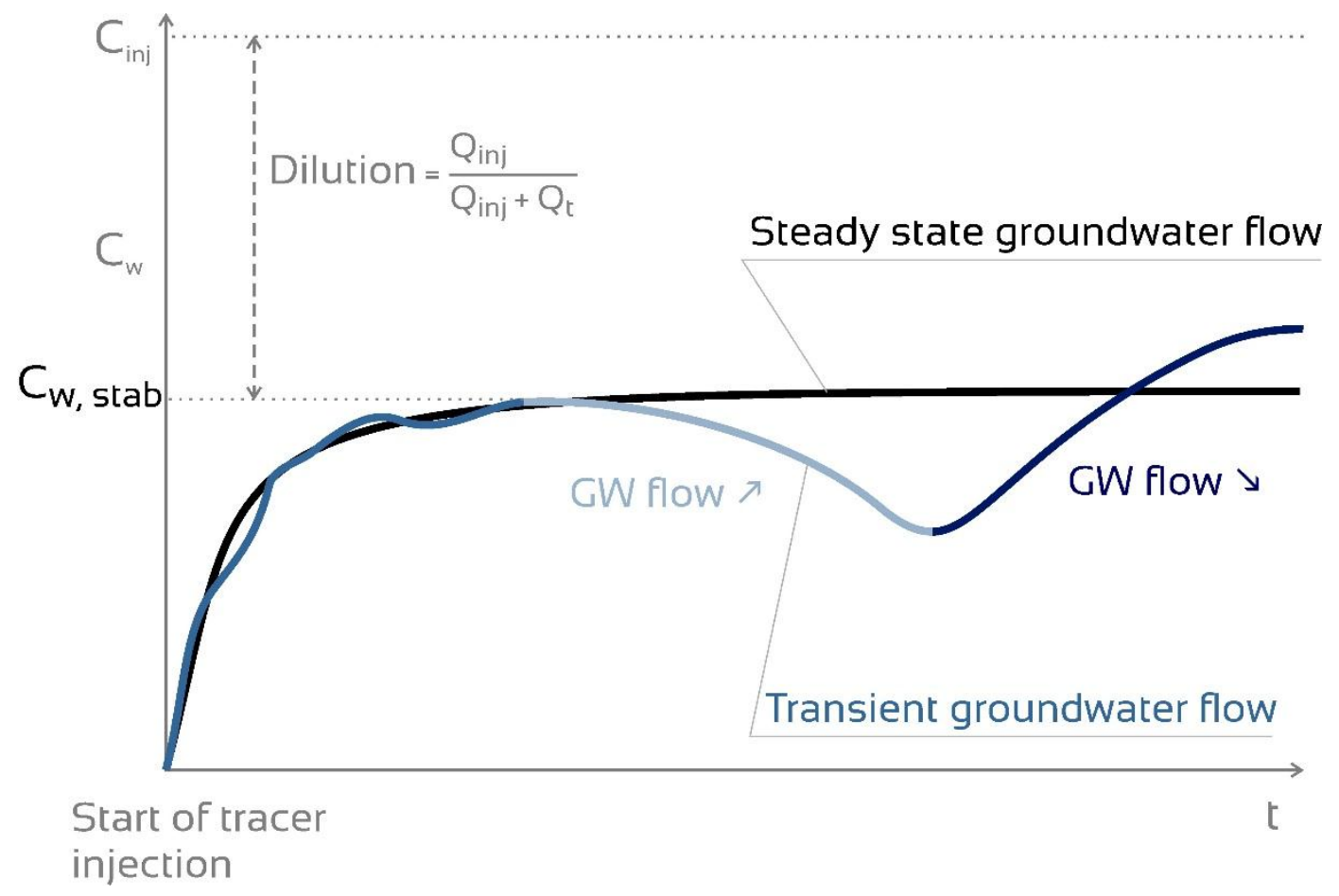

510 Figure 2: Typical temporal evolution of tracer concentration in a well, which is tested by FVPDM. The

511 black curve corresponds to the steady state groundwater flow condition with a stabilization at a

512 concentration $\mathrm{C}_{\mathrm{w} \text {, stab. }}$. The blue curve corresponds to transient state groundwater flow conditions. If

513 groundwater flow decreases (dark blue), the tracer is less diluted in the well, and its concentration

514 increases. If the groundwater flow increases (light blue), the tracer is more diluted in the well, and its

515 concentration decreases. 


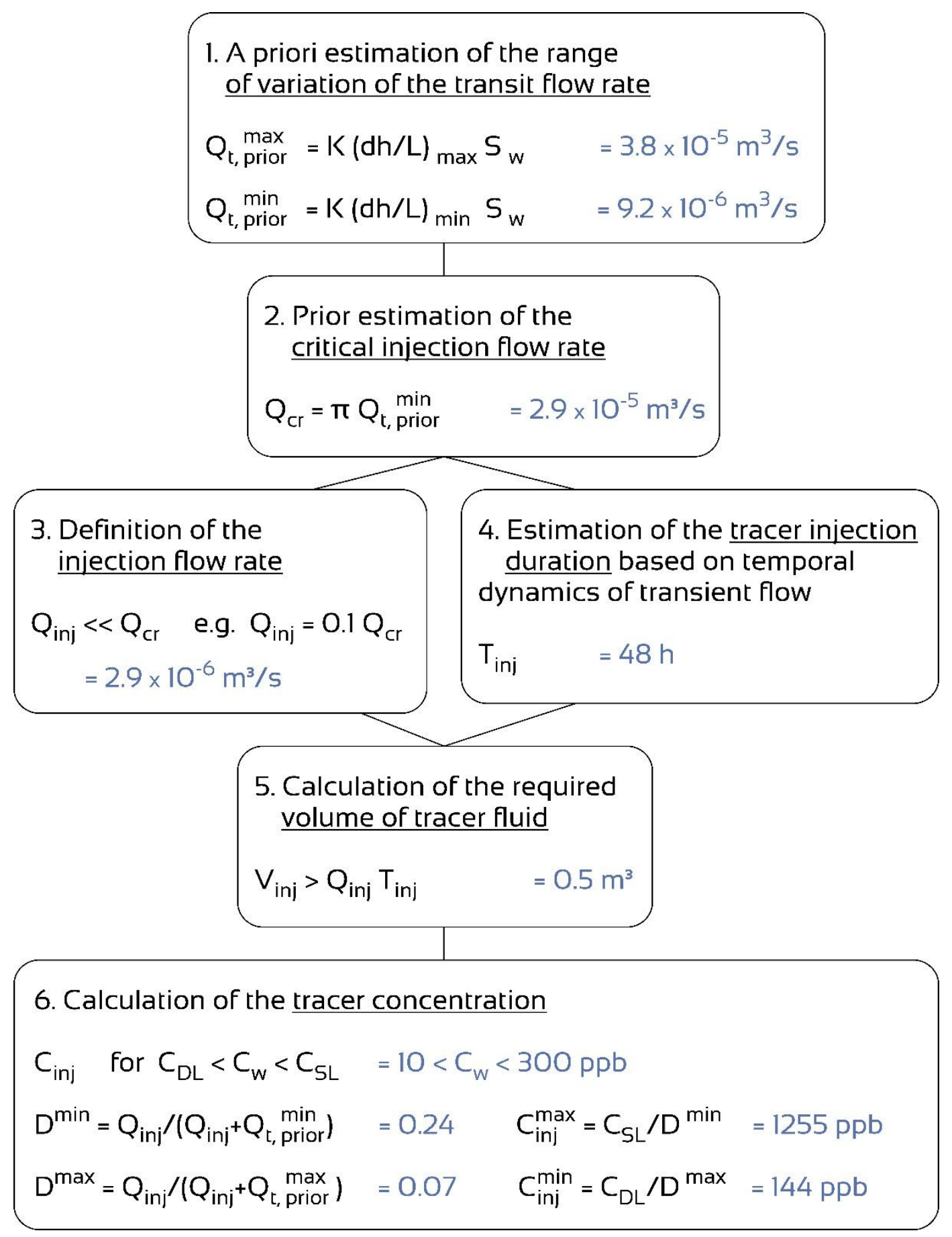

517 Figure 3: Flow chart of the dimensioning of the optimal FVPDM experimental configuration for

518 continuous monitoring of transient groundwater flux. Values indicated in the different boxes of the

519 flow chart are those obtained when dimensioning the FVPDM experiment undertaken at piezometer Pz19_deep (see next section) considering data summarized in Table 1. 

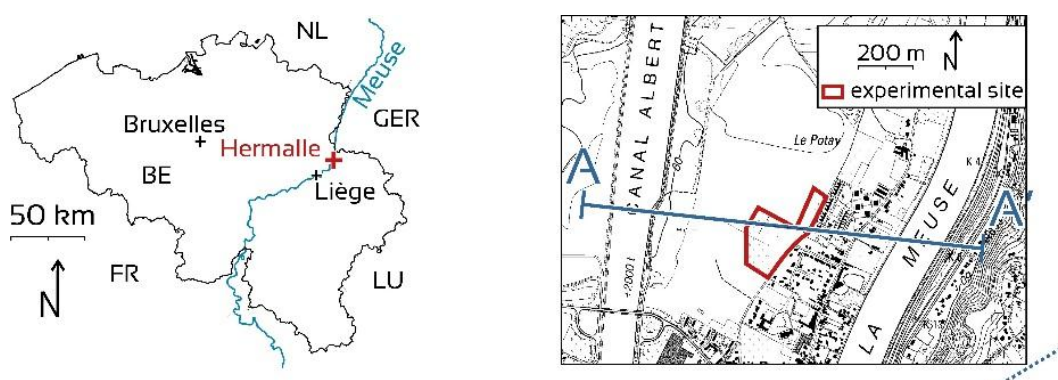

A

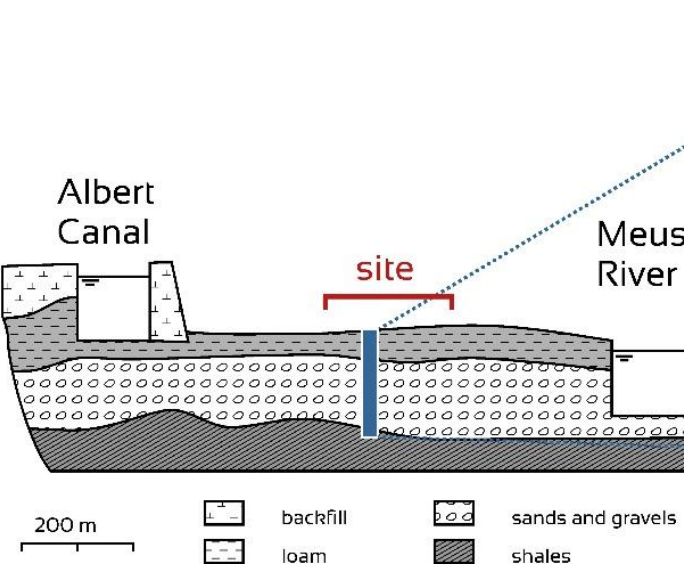

$A^{\prime}$

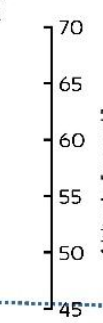

Depth

0 .

10

2.0

3.0

4.0

5.0

6.0

7.0

8.0

9.0 10.0

Shaly bedrock

522 Figure 4: The test site is located on the alluvial plain of the River Meuse, which is $13 \mathrm{~km}$ northeast of

523 Liège, Belgium in Western Europe. The aquifer is composed of sandy gravels that becomes coarser to

524 the base. Hydraulic conductivity is approximately $5 \times 10^{-2} \mathrm{~m} / \mathrm{s}$ (Brouyère, 2001). 


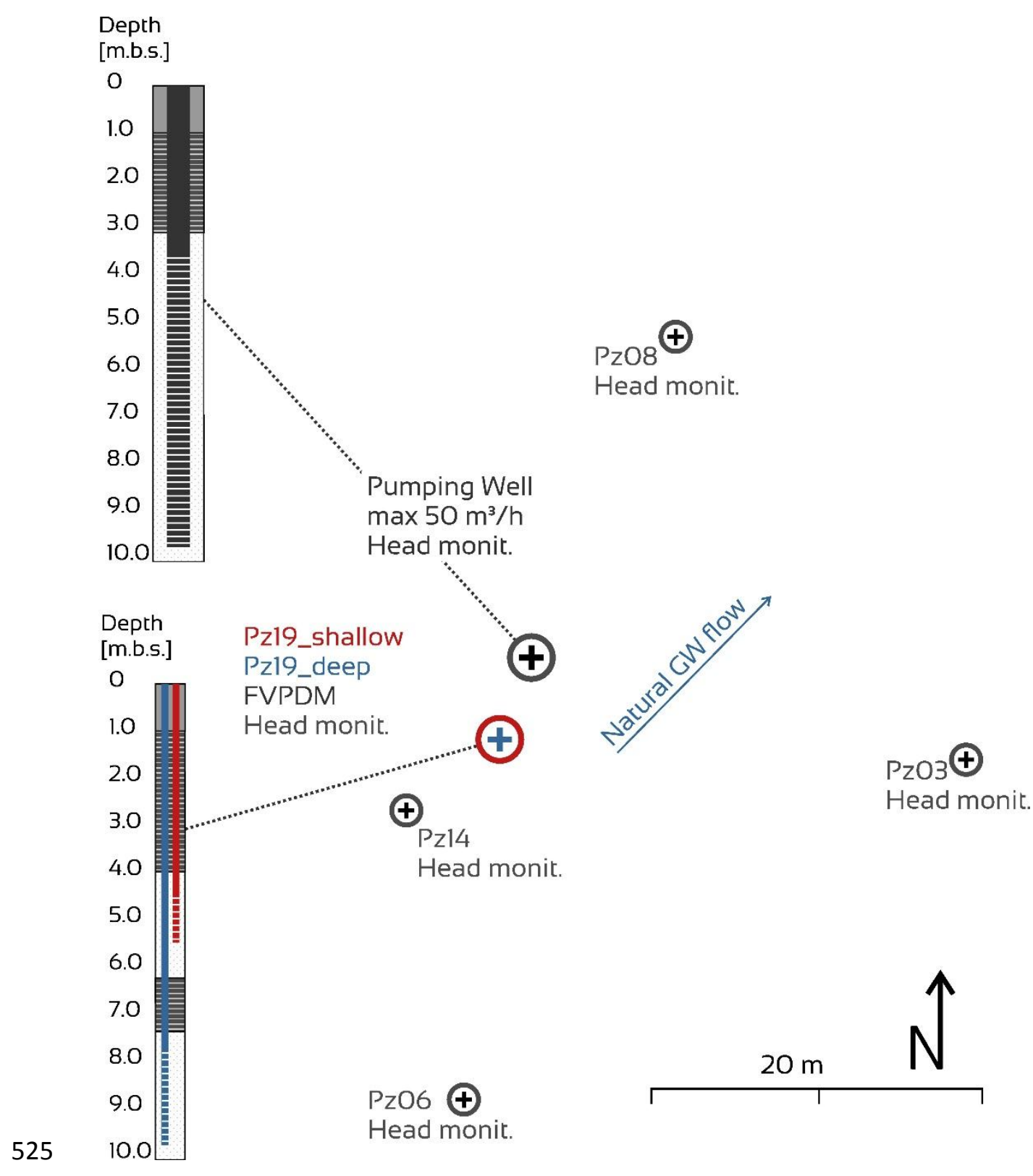

526 Figure 5: The experimental configuration consists of a typical pumping test arrangement with

527 piezometric head monitoring at 6 piezometers around the pumping well. The originality of the

528 experiment involved performing the FVPDM continuously during the whole pumping test at two

529 piezometers, which were located $5 \mathrm{~m}$ up gradient from the pumping well. These two piezometers are

530 either screened in the upper, finer part of the aquifer or in the lower, coarser part of the aquifer. 

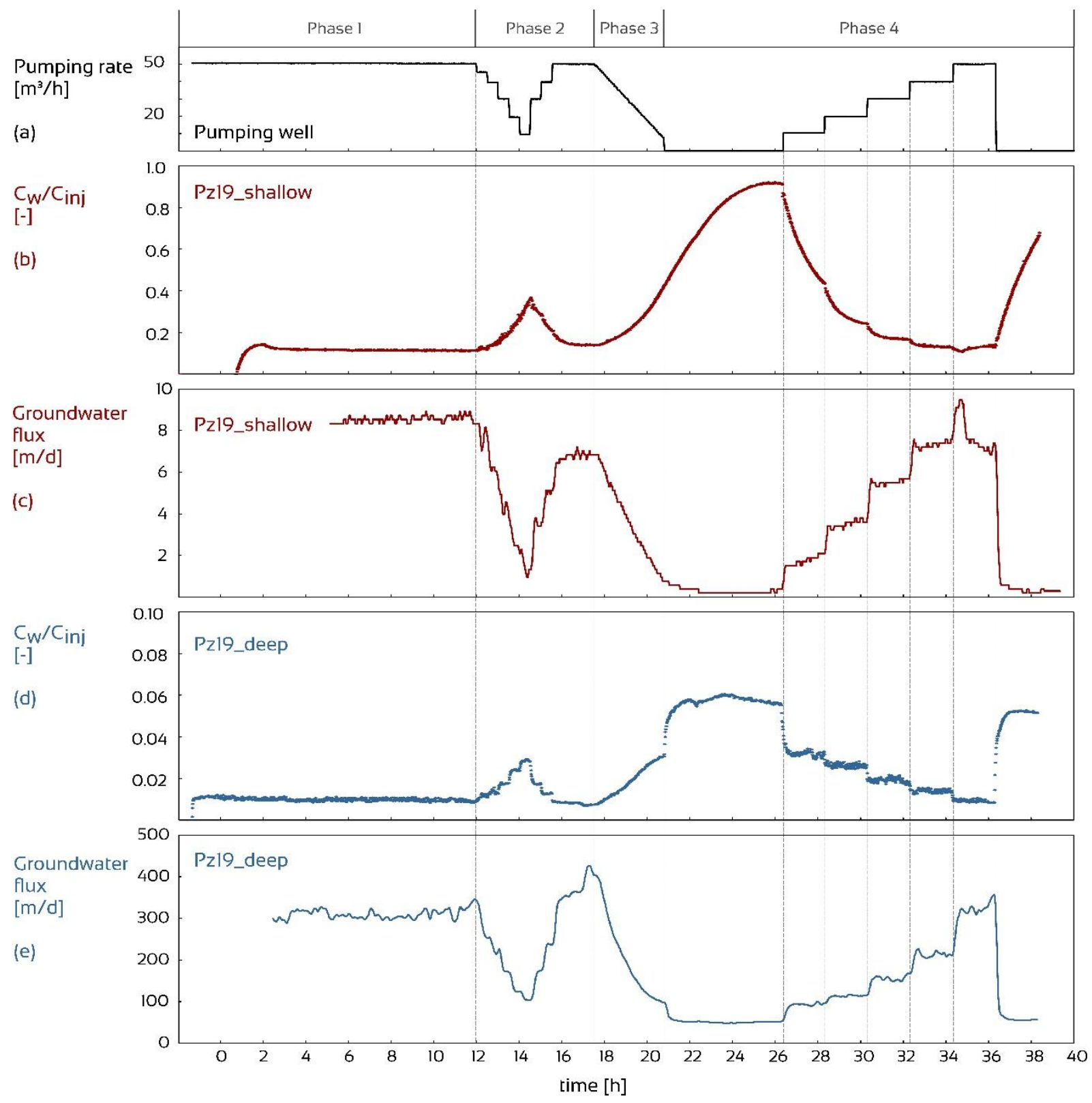

Figure 6: Graph (a) shows the pumping rate schema applied at the well. Graphs (b) and (c)

533 respectively represent the tracer concentration evolution, and the interpretation of the FVPDM into

534 Darcy's fluxes for piezometer Pz19_shallow. Graphs (d) and (e) show tracer concentration and

535 groundwater flux for Pz19_deep. These interpretations show that the groundwater flux is higher in

536 the lower part of the aquifer and that the FVPDM can monitor changes in groundwater fluxes. Please

537 note that the maximum ordinate scales for Pz19_shallow and Pz19_deep differs of one order of

538 magnitude for the relative concentration and is 50 times higher for the interpreted groundwater flux. 


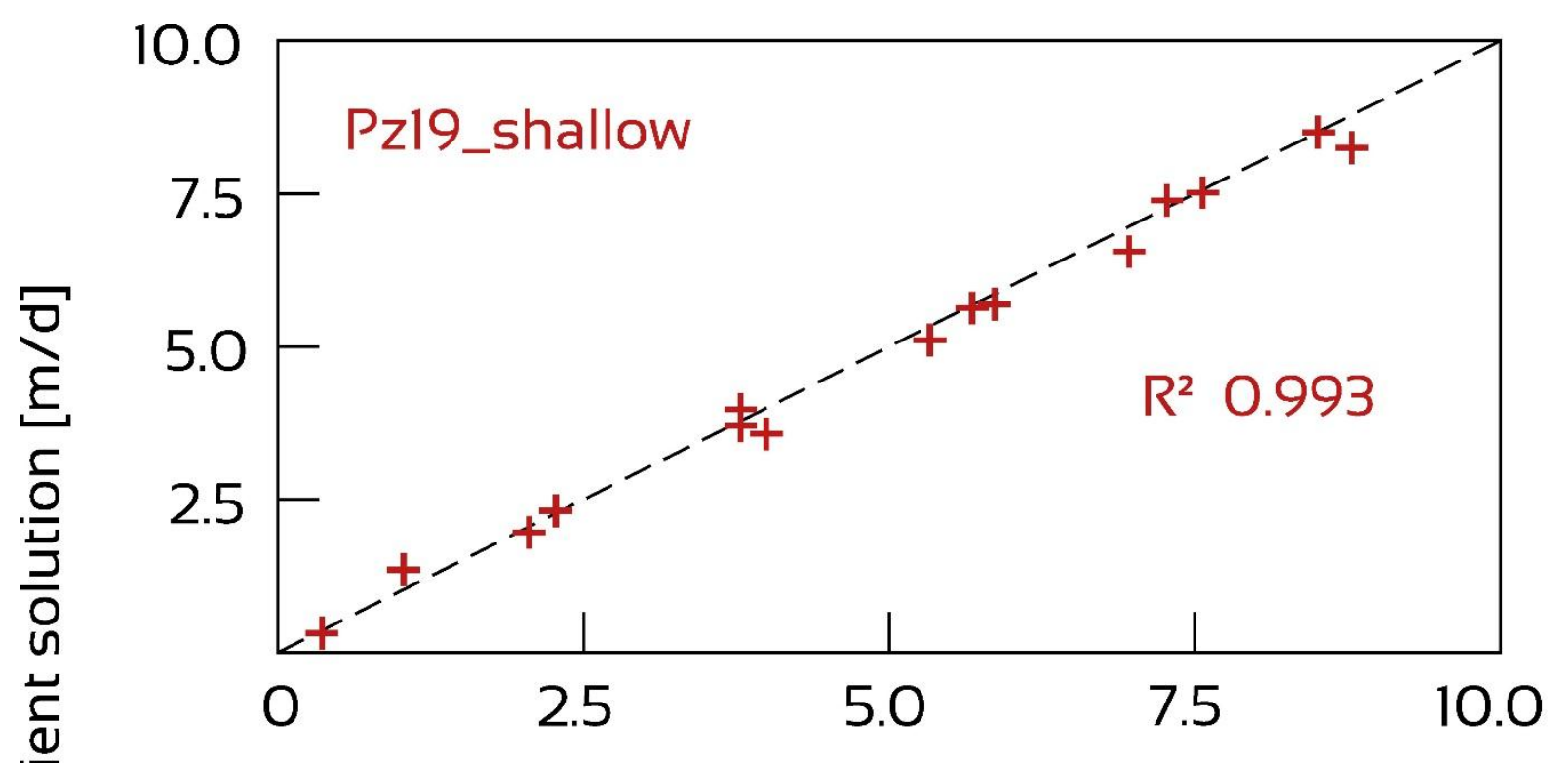

$540 \quad$ Figure 7: The groundwater fluxes calculated with the new transient solution agree well with the

541 values that have been manually adjusted on the same experimental result using the Brouyère et al.

542 (2008) analytical solution. 

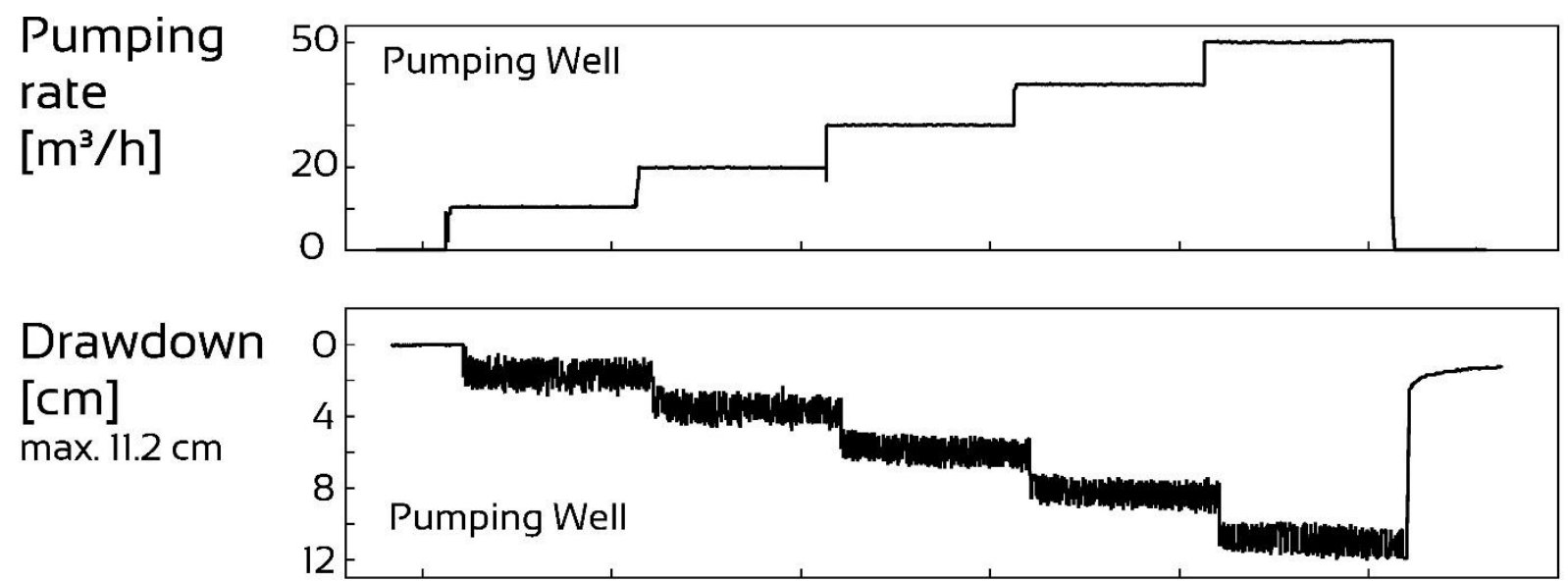

Drawdown [cm] $\max 6.6 \mathrm{~cm}$

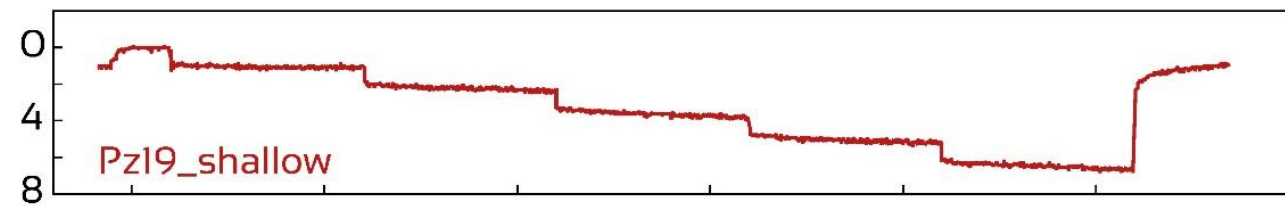

Drawdown [cm] $\max 6.8 \mathrm{~cm}$

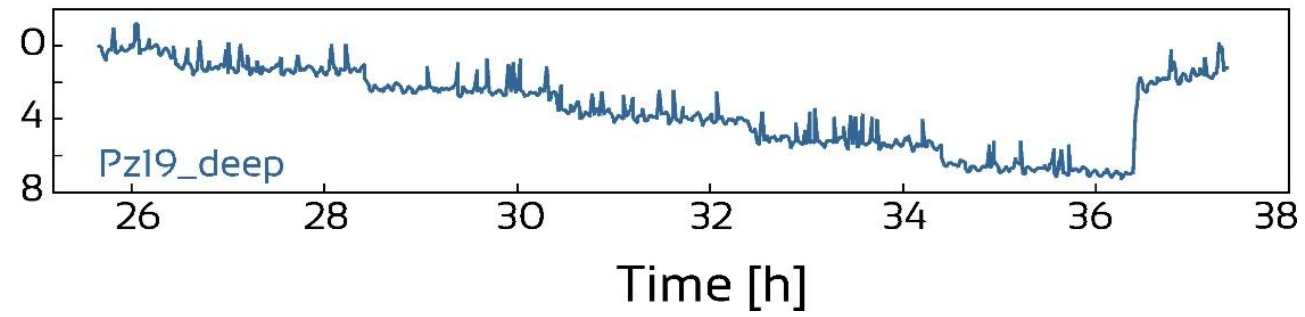

544 Figure 8: The drawdown measured at the two Pz19 piezometers, up and low, are identical suggesting

545 an identical reaction of the upper and lower zones of the aquifer to pumping. The interpretation of

546 this pumping test using the Dupuit method gives a hydraulic conductivity of $3.26 \times 10^{-2} \mathrm{~m} / \mathrm{s}$. 

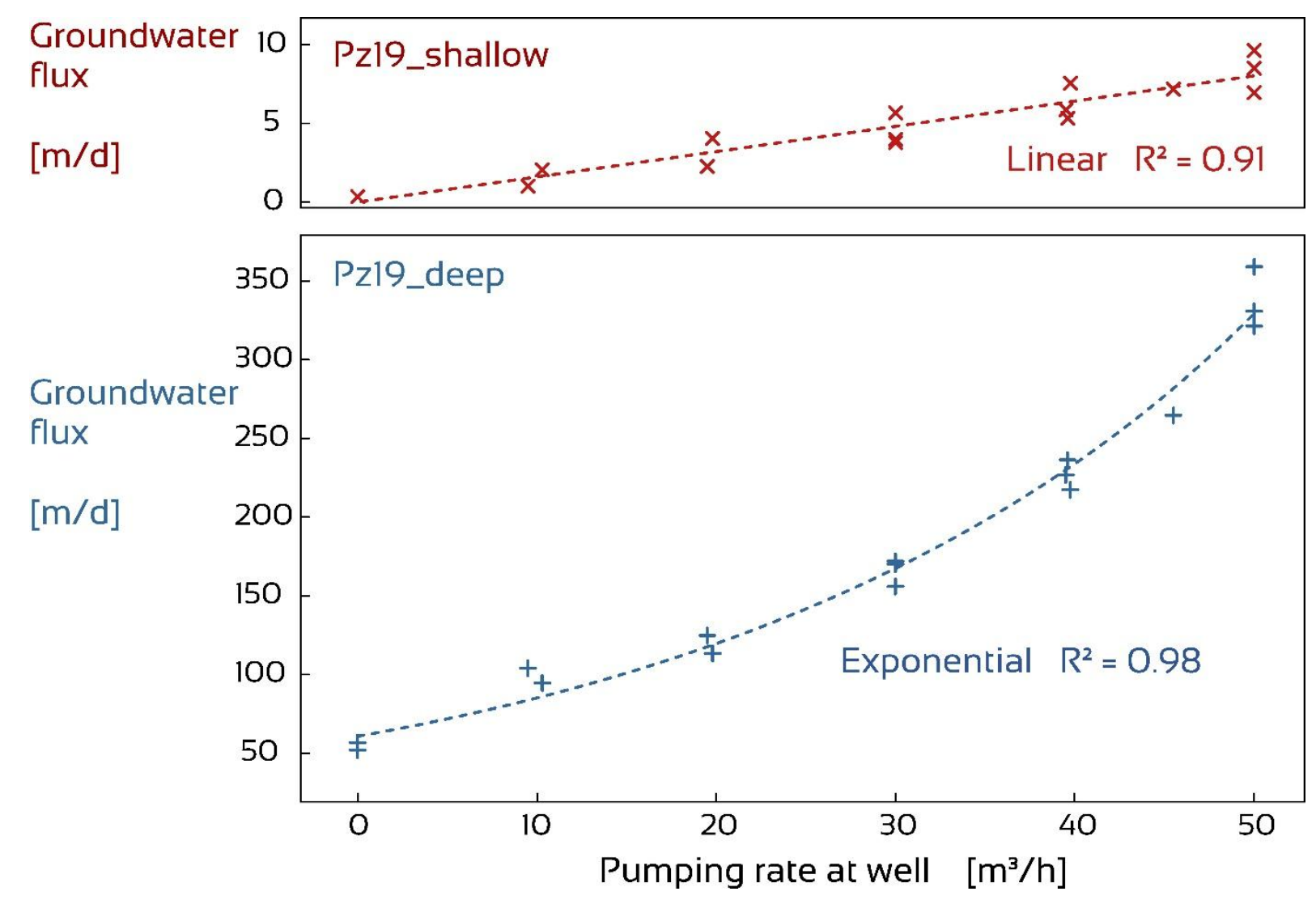

547

Figure 9: The groundwater flux evolution with pumping is exponential when measured at Pz19_deep,

549 but it remains linear at Pz19_shallow. 


\section{Supplementary Material 1: Calculation of the distortion coefficient $\alpha_{w}$}

551 The existence of a well or piezometer induces a local distortion of the groundwater flow field (Drost et

552 al. 1968, Verreydt et al. 2014). The difference between the effective groundwater flux occurring in the

553 aquifer and the apparent water flux measured in the tested well depends on the well construction

554 characteristics such as the thickness and hydraulic conductivity of the gravel pack and the hydraulic

555 conductivity of the well screen. This distortion coefficient is usually calculated through the flow

556 distortion or convergence/divergence factor $\left(\alpha_{w}\right)$ which characterizes the degree of convergence or

557 divergence of groundwater flow in the vicinity of the monitoring well. In this study, the presented

558 groundwater fluxes resulting from the FVPDM experiment are apparent Darcy fluxes and are not

559 corrected using the convergence/divergence factor.

560 For a piezometer constructed with a filter pack, the convergence/divergence factor can be calculated

561 as follow (Drost et al. 1968):

562

$\alpha_{w}=\frac{8}{\left(1+\frac{k_{A}}{k_{F}}\right)\left(\left(1+\left(\frac{r_{I}}{r_{O}}\right)^{2}\right)+\frac{k_{F}}{k_{S}}\left(1-\left(\frac{r_{S}}{r_{B}}\right)^{2}\right)\right)+\left(1-\frac{k_{A}}{k_{F}}\right)\left(\left(\frac{r_{I}}{r_{B}}\right)^{2}+\left(\frac{r_{O}}{r_{B}}\right)^{2}\right)+\left(\frac{k_{F}}{k_{S}}\right)\left(\left(\frac{r_{I}}{r_{B}}\right)^{2}-\left(\frac{r_{O}}{r_{B}}\right)^{2}\right)}$

Where $k_{A}$ is the hydraulic conductivity of the aquifer, $k_{F}$ the hydraulic conductivity of the filter pack,

$k_{S}$ the hydraulic conductivity of the well screen. $r_{l}$ is the internal radius of the well screen, $r_{O}$ is the outer radius of the filter screen and $r_{B}$ is the radius of the borehole.

The properties of the monitoring wells of the Hermalle-sous-Argenteau test site are given in table S1.

The hydraulic properties of the gravel filter pack and of the well screen were provided by the

manufacturer. Using these properties in Equation S1 give a convergence factor of 2.87 .

\begin{tabular}{ll}
\hline Radius of the borehole $r_{B}[\mathrm{~m}]$ & 0.09 \\
\hline Inner radius of the well screen $r_{l}[\mathrm{~m}]$ & 0.025 \\
\hline
\end{tabular}




\begin{tabular}{ll}
\hline Outer radius of the well screen $r_{O}[\mathrm{~m}]$ & 0.03 \\
\hline Hydraulic conductivity of the aquifer $k_{A}[\mathrm{~m} / \mathrm{s}]$ & $3.26 \times 10^{-2}$ \\
\hline Hydraulic conductivity of the filter pack $k_{F}[\mathrm{~m} / \mathrm{s}]$ & $3.97 \times 10^{-1}$ \\
\hline Hydraulic conductivity of the well screen $k_{s}[\mathrm{~m} / \mathrm{s}]$ & $2.90 \times 10^{-1}$
\end{tabular}

571

572 
573 Supplementary Material 2: Monitoring of the groundwater levels

574 during the FVPDM experiments

575
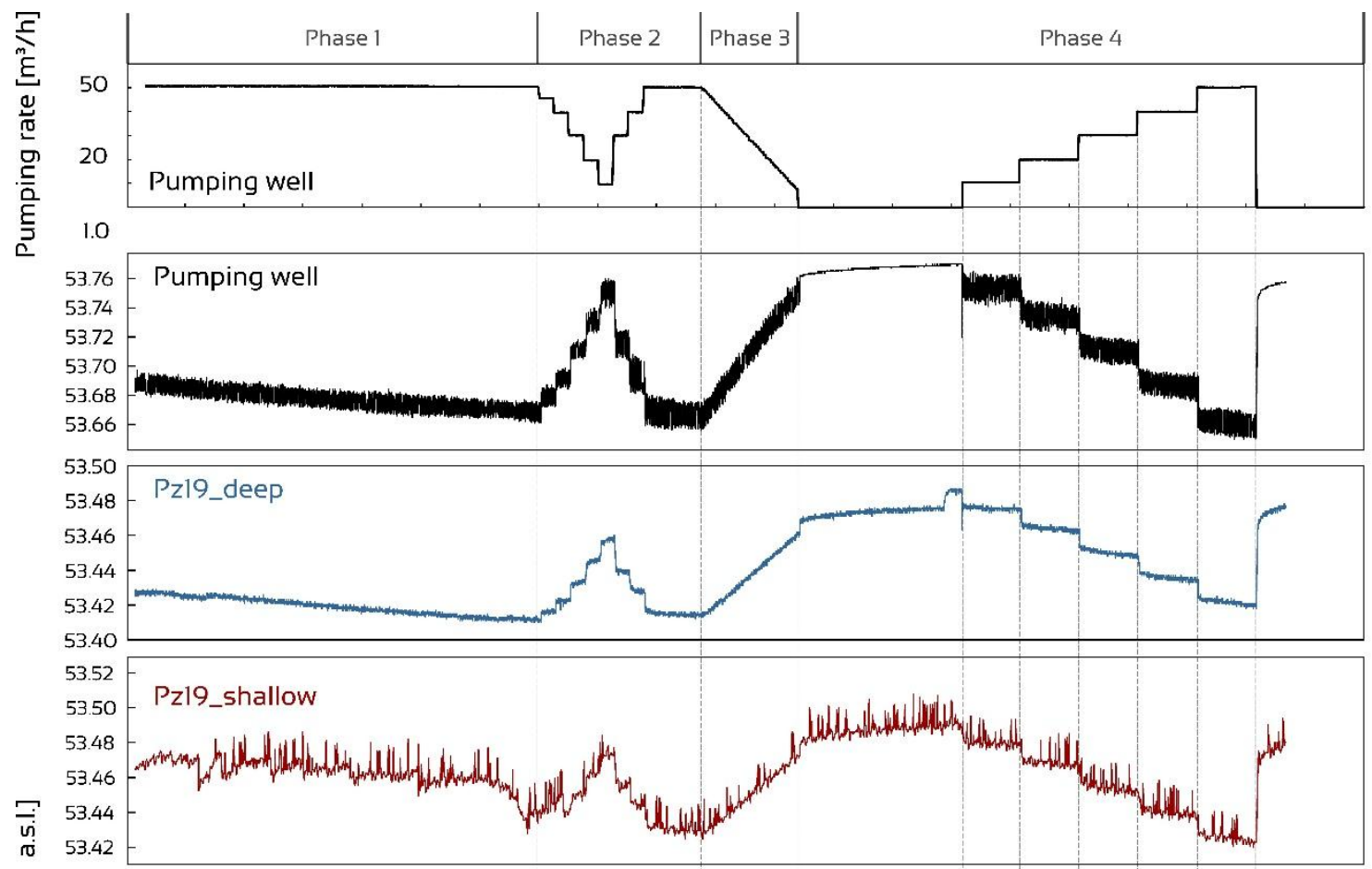

$\varepsilon$
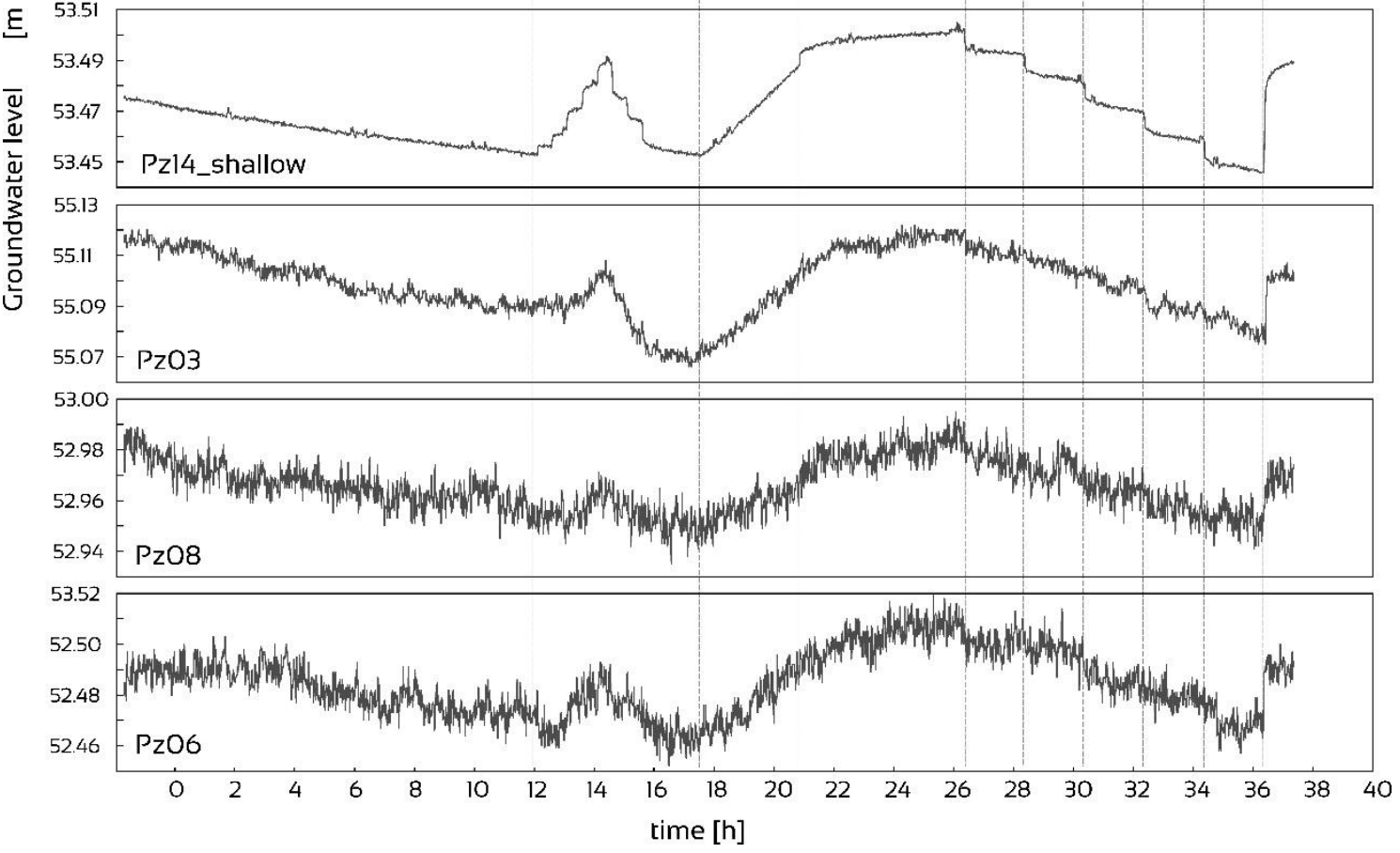

577 Figure SM1: Monitoring of the groundwater levels at Pumping Well, Pz19_deep, Pz19_shallow,

578 Pz14_shallow, Pz03, Pz08 and Pz06 during the whole time of the pumping test and FVPDM

579 experiments. 
581 Supplementary Material 3: Steady state interpretation of the

582 pumping test

583

584

The pumping steps applied between 25 and 38 hours into the test can be interpreted like a

585

conventional pumping test to estimate the hydraulic conductivity near the pumping well. The

piezometric drawdown has been recorded at 5 piezometers located around the well. For each pumping

rate the drawdowns at the piezometers are plotted as a function of their distance to the pumping well

as recommended by the Dupuis method. The fact that the calculated values of $\mathrm{H}^{2}-\mathrm{h}^{2}$ (at the pumping

well and at the different monitored piezometers) align perfectly indicates that the Dupuit hypothesis

591 from the slope of the linear regression adjusted for each pumping rate. The mean hydraulic conductivity for the tested alluvial aquifer is $0.0326 \mathrm{~m} / \mathrm{s}$.

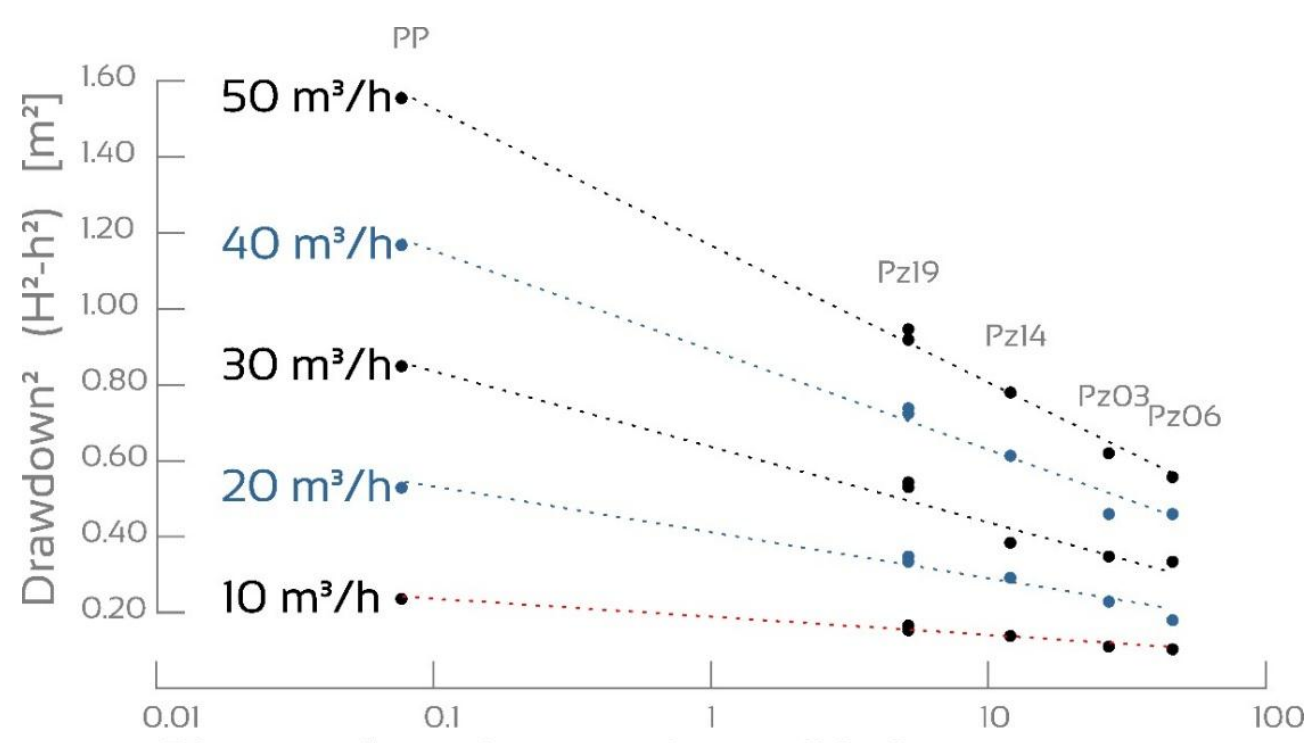

Distance from the pumping well [m]

Hydraulic conductivity $\left[\times 10^{-2} \mathrm{~m} / \mathrm{s}\right]$

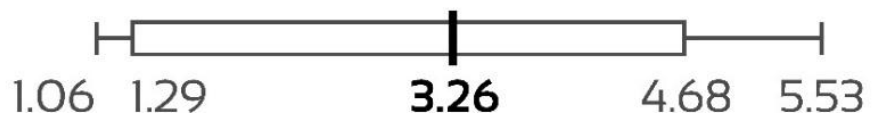


594 Figure SM2: Interpretation of the pumping test using the Dupuis method. The mean hydraulic 595 conductivity is $0.0326 \mathrm{~m} / \mathrm{s}$. 